\title{
IMPORTÂNCIA DO ESTAGIO CURRICULAR SUPERVISIONADO NA VISÃO GERENCIAL DO ACADÊMICO DE ENFERMAGEM
}

\author{
Francine Santellano Susin 1 ; Manuela da Silva Couto²; Adriana Pereira \\ Dall'Asta ${ }^{3}$; Carla Lizandra de Lima Ferreira ${ }^{4}$
}

\section{RESUMO}

Objetivo: Relatar a experiência discente durante o estágio curricular supervisionado em enfermagem II em uma unidade cirúrgica a cerca das checagens/aprazamentos das prescrições médicas e de enfermagem, e da importância da educação permanente no serviço. Metodologia: Se trata de um relato de experiência realizado durante a disciplina de estágio curricular supervisionado em enfermagem I, do Curso de Enfermagem da Universidade Franciscana, disciplina, realizado no período de março a junho de 2021.Resultado e discussão: as ações educacionais precisam observar a realidade do local para utilizar as temáticas necessárias, porém, é necessário aprender a ler a realidade para que se possa transformá-la e após utilizar-se de aportes teóricos, e ter a conciência que nem todas as vezs elas alcançam as expectatvas que gostaria-se Conclusão: A ação em questão apresentada, através da realização de uma educação permanente, mas ao final mesmo parecendo ineficaz me fez refletir muito sobre a prática da enfermagem e o seu respaldo, que necessicitamos fazer a nossa parte e registrar o que foi realizado enão desistir de tentar educar e ensinar a nossa equeipe.

Palavras-chave: Aprazamento das prescrições; Educação Permanente; Enfermagem;

Eixo Temático: Atenção Integral e Promoção à Saúde.

\footnotetext{
1 Acadêmico do Curso de Enfermagem - UFN. Membro do GEPESES. Email: franssusin@gmail.com

2 Enfermeira. Email: manuela_couto@outlook.com

${ }^{3}$ Orientadora - Enfermeira - Doutora, Professora do Curso de Enfermagem - UFN. Membro do GEPESES. Email: adrianadallastapereira@gmail.com

${ }^{4}$ Orientadora - Enfermeira - Doutora, Professora e Coordenadora do Curso de Enfermagem - UFN. Membro do GEPESES.Email: carlafer@ufn.edu.br
} 


\section{INTRODUÇÃO}

A enfermagem é a profissão que possui o maior número de profissionais atuante nos serviços de saúde, sendo também a única profissão a ficar em contato com os pacientes por 24 horas. São esses profissionais que se responsabilizam pela atenção integral à saúde de quem demanda seus cuidados. Sendo assim, a formação dos (as) profissionais de enfermagem está diretamente ligado a construção do perfil que o mundo do trabalho espera e necessita, não sendo apenas relacionado aos conhecimentos biológicos e técnicos, é sim sendo essencial que o acadêmico tenha um perfil crítico e que possa contribuir para a sociedade. Desta forma, as estratégias que integrem teoria e prática são fundamentais para um currículo e formação desse profissional e possam possibilite 0 melhor aproveitamento dos estudantes (OLIVEIRA; GRIBOSKI, 2018). De forma que a estratégia fundamental para cumprir esse objetivo é 0 estágio curricular supervisionado.

Segundo as Diretrizes Curriculares Nacionais (DCN) do curso de graduação em Enfermagem, "ficam os cursos de enfermagem, obrigados a incluir no currículo o estágio supervisionado em hospitais gerais e especializados, ambulatórios, rede básica de serviços de saúde e comunidades" (MEC, 2001 pag. 5). Este tem o objetivo de capacitar os profissionais com as habilidades e competências necessárias para a sua formação.

Observando assim, que o Estágio Supervisionado de Enfermagem é um dos momentos final que alia a teoria e prática estabelecidos ao longo dos semestres cursados. Nesta oportunidade o acadêmico precisa se posicionar como profissional possibilitando o aperfeiçoamento do aprendizado técnico, crítico e posteriormente o desenvolvimento da autonomia e segurança para exercer sua futura profissão. Estabelece a etapa cujo acadêmico é inserido nos serviços de saúde, sem a presença diária do professor e com a supervisão de um profissional enfermeiro do local que o supervisiona, para assim poder desenvolver as competências necessárias a um profissional da categoria. 
Logo, este momento gera o contato direto com profissionais, com pacientes e com conflitos e situações que surgem no dia a dia do enfermeiro, com as demandas dos locais em que estarão inseridos como aprendizes e, também como profissionais habilitados, a depender do relacionamento estabelecido com a equipe. Considera-se esse momento rico, cheio de oportunidades de aperfeiçoamento profissional diante de situações seja na assistência direta ao paciente, no gerenciamento e gestão dos serviços prestados pela local e na construção do relacionamento interpessoal entre todos os envolvidos nas etapas do cuidado de enfermagem, fundamentais para a formação do enfermeiro (OLIVEIRA; GRIBOSKI, 2018).

\section{OBJETIVO}

Relatar a experiência discente durante o estágio curricular supervisionado em enfermagem II em uma unidade cirúrgica a cerca das checagens/aprazamentos das prescrições médicas e de enfermagem, e da importância da educação permanente no serviço.

\section{METODOLOGIA}

O presente trabalho é de caráter descritivo, do tipo relato de experiência, realizado a partir da vivência discentes no Estágio Curricular Supervisionado em Enfermagem II (ECS II) do Curso de Enfermagem da Universidade Franciscana (UFN). Realizado no período de julho a outubro de 2020, totalizando 300 horas. De acordo com Gil (2008), o relato de experiência da margem para o pesquisador relatar suas experiências e vivências junto com o saber científico e assim contribuindo de forma relevante para sua área de atuação.

O local de realização do ECS II foi em uma Unidade Cirúrgica pertecente a um Hospital de médio porte, no qual é um estabelecimento de saúde $100 \%$ SUS do tipo Hospital Geral que executa serviços de saúde, localizado na Região Norte da cidade de Santa Maria-RS.De forma que o fluxo de atendimento da unidade é por agendamento, salve cirurgias de urgência nas quais o hospital comporte. 0 
recebimento de pacientes na unidade é provido de cirurgias realizadas dos tipos de traumatologia, ginecologia, oftalmologia, cirurgia plástica, vascular, cirurgias gerais. Além disso, o hospital possuir realização de exames para pacientes internados como radiologia, tomografia computadorizada, ultrassonografia, ecocardiograma, endoscopia e colonoscopia.

\section{RESULTADOS E DISCUSSÃO}

Durante o curso de enfermagem, ao realizarmos o ECS II é solicitado ao academico a realização de alguma ação estratégica a partir do diagnóstico situacional do cenário que esta inserido. As mesmas tem o objetivo de auxiliar na demanda observadas no processo de trabalho de enfermagem nas unidade e também na qualificação do serviço prestado no local onde é desenvolvido o estágio.

Desta forrma, através da observação da unidade durante os primeiros dias de estágio e a realização do diagnóstico situacional, em consenso com a enfermeira foi necessário realizar uma educação permanente diante de uma demanda da unidade.Com o passar dos dias, e com a frequência da revisão das pastas dos pacientes, foram observadas algumas falhas relacionadas as checagens/aprazamentos das prescrições médicas e de enfermagem. A partir disso, houve a necessidade de realizar uma educação permanente sobre essa temática, focando a importância desta checagem e o que pode gerar se não for checado. Observa-se que os medicamentos são um dos principais recursos usados na terapêutica do paciente, sendo assim, os eventos adversos e os erros relacionados a medicamentos ocorrem frequentemente no ambiente hospitalar. A prescrição é realizada pelo profissional médico, contudo, o aprazamento e administração fazem parte da rotina da enfermagem (ANDRADE, 2018).

Ressalta-se que o processo de administração de medicamentos é considerado crítico, complexo e de alto risco para os pacientes e possui altas taxas de ocorrências de eventos adversos evitáveis. Existem várias causas que geram os eventos adversos, dentre elas está o aprazamento inadequado ou não realizado. $O$ aprazamento é um cuidado relacionado a prescrição médica, porém de 
responsabilidade da equipe de enfermagem. Ao realizar esta atividade precisa-se adotar práticas seguras evitando comprometer a assistência do paciente (ANTUNES; PILAU, 2011).

Reforça-se ainda que a prescrição de enfermagem é uma das atribuições privativas do enfermeiro e faz parte da Sistematização da Assistência de Enfermagem (SAE). Por meio da SAE realiza-se a identificação das as necessidades de cada paciente para amparar a prescrição das ações de enfermagem, tendo o foco na promoção, prevenção, recuperação e reabilitação da saúde do paciente. A prescrição de enfermagem contempla um conjunto de medidas que tem o objetivo de fornecer um cuidado individualizado e centrado na necessidade do paciente, integrando a equipe de enfermagem e o enfermeiro, direcionando à assistência humanizada (CORRÊA et al., 2016).

Com essa contextualização para basear a realização da Educação Permanente (EP) percebe-se que o aprazamento da prescrição médica e de enfermagem é fundamental para qualidade na assistência do paciente. Ainda revidencia-se que, se o curativo realizado no paciente não está checado o hospital não recebe a verba da realização do mesmo, reforçando como é importante essa checagem.

Para realização da Educação Permanente, não foi possível juntar todos os funcionários em um mesmo horário, sendo necessário fazer a mesma de forma fracionada, ou seja em diferentes turnos e horários. Em um dos momentos foi realizado o encontro uma hora antes do final do plantão da noite em conjunto com a enfermeira para realização da ação de sensibilização dos colaboradores sobre a necessidade da checagem. Salienta-se que a EP é uma ferramenta de grande relevância para a gestão, para auxiliar nas melhorias dos cuidados aos pacientes e a capacitação dos seus profissionais (CAMPOS; SENA; SILVA, 2017). Recebi da enfermeira um feedback positivo das orientações do momento da minha fala e da clareza ao demonstrar a importância desta temática.

Reforça-se que a EP é uma forma de aprendizagem no ambiente de trabalho, no qual o ensinar e o aprender se complementam. Observa-se que os processos de capacitação dos profissionais da saúde tomem como referência as 
necessidades de saúde da população e das pessoas, do controle social em saúde e da gestão setorial, tendo como objetivos a transformação das práticas profissionais e da própria organização do trabalho, átravés de uma problematização do processo de trabalho. Sendo que a EP pode ser observada como 0 aperfeiçoamento contínuo das competências do acadêmico (aprender a aprender), significando que os locais de serviços para as práticas curriculares gerariam um cenário ideal para o processo de aprendizagem, e que a troca de experiência entre os profissionais e academicos gera uma melhoria na continuidade dos processos (SAMPAIO et al., 2019).

Realizamos a EP e após a confecção da ata da mesma e os profissionais assinaram. Porém, mesmo conseguindo apresentar de forma efetiva o tema, me deparei com a continuação das falhas na checagem após a realização da educação permanente. Observa-se que a ata de uma reunião, possui a configuração de transformar o que foi falado para a forma escrita, sendo utilizada no contexto profissional para manter o registro de decisões e argumentos que foram previamente apresentados durante as reuniões e pactuados com o grupo. Reforçando a importancia da confecção da ata após cada reunião e a assinatura dos participantes, pois fica respaldado por escrito o conteúdo explanado.

Nesse sentindo, mesmo parecendo que não foi eficaz a educação permanente, foi de grande valia para meu crescimento profissional para perceber que nem sempre as coisas dão certo, porém precisamos nos respaldar do que foi realizado, como foi realizado pela descrição da ata e assinatura dos profissionais, pois caso aconteça um erro que prejudique o paciente referente ao que foi falado, temos nosso respaldo legal do que passamos para a equipe.

Por fim, reforça-se que as ações educacionais tem como objeto observar a realidade do local para observar as temáticas necessárias, porém, é necessário aprender a ler a realidade para que se possa transformá-la e após utilizar-se de aportes teóricos que ampliem o olhar crítico dos trabalhadores, profissionais e gestores nos serviços de saúde. Sendo assim, caracteriza-se a educação permanente, demandada pelos sujeitos que estão mergulhados no cotidiano e a 
complexidade de seus problemas, necessitando mudanças nos modos de se realizar a atenção à saúde (CAMPOS; SENA; SILVA, 2017).

\section{CONSIDERAÇÕES FINAIS}

Este estágio foi de grande valia para o meu crescimento pessoal e profissional, foi desafiador principalmente pessoalmente e ao mesmo tempo prazeroso. Consegui visualizar a gestão e gerência da enfermeira em uma unidade hospitalar, com todos os problemas que podem surgir e a importância da tomada de decisão na vida profissional do enfermeiro, podendo futuramente aplicar isso em minha vida profissional. Visualizei de forma eficaz o trabalho em equipe e uma boa comunicação entre os seus membros para que o cuidado seja de qualidade, sendo que com certeza quero seguir o exemplo que vivencie de uma enfermeira líder que entende sua equipe e consegue se comunicar com ela.

A ação em questão apresentada, através da realização de uma educação permanente, que sempre me desafia a fala, mas ao final mesmo parecendo ineficaz me fez refletir muito sobre a prática da enfermagem e o seu respaldo, que necessicitamos fazer a nossa parte e registrar o que foi realizado e não desistir de tentar educar e ensinar a nossa equipe.

\section{REFERÊNCIAS}

ANDRADE, T. M. et al. A importância da enfermagem para o aprazamento correto das medicações. In: Conexão Fametro 2018, Fortaleza/CE, 2018.

ANTUNES, J. C. D. F.; PILAU, C. Aprazamento de medicamentos - prática profissional da equipe de enfermagem. In XVI Seminário interinstitucional de Ensino Pesquisa e Extensão. Unicruz. Out. 2011.

BROCA, P. V.; FERREIRA, M. A. Equipe de enfermagem e comunicação: contribuições para o cuidado de enfermagem. Rev. bras. enferm., Brasília, v. 65, n. 1, p. 97-103, fev. 2012. 
CARLESI, K. C. et al. Ocorrência de incidentes de Segurança do Paciente e Carga de Trabalho de Enfermagem. Rev. Latino-Am. Enfermagem, Ribeirão Preto, v. 25, e2841, 2017 .

CAMPOS, K. F. C.; SENA, R. R.; SILVA, K. L. Educação permanente nos serviços de saúde Escola Anna Nery Revista de Enfermagem, v. 21, n. 4 , p. 1-10, 2017.

CORRÊA, R. U.; et al. A importância da prescrição de enfermagem para um cuidar sistematizado. IN: 13ª Mostra de Iniciação Científica. Congrega, Urcamp, 2016.

COSTA, C. U.; ALVES, P. S.; ERLER. Avaliação da aplicabilidade da escala de morse para gerenciamento do risco de quedas em ambiente hospitalar. Rev. Esfera Acadêmica Saúde, v. 1, n. 2, 2016.

DALRI, R. C. M. B.; et al. Carga horária de trabalho dos enfermeiros e sua relação com as reações fisiológicas do estresse. Rev. Latino-Am. Enfermagem, v. 22, n. 6, p. 959-965, nov.-dez. 2014.

FERREIRA, N. C. B., et al. Checklist de Cirurgia Segura: Conhecimento e Utilização do Instrumento na Perspectiva dos Técnicos de Enfermagem. Revista de Enfermagem do Centro Oeste Mineiro. v. 9. 2019.

GAUER, A. P. M. et al. Ações de reorientação da formação profissional em Fisioterapia: enfoque sobre cenários de prática. Interface (Botucatu), Botucatu, v. 22 , n. 65, p. 565-576, abr. 2018.

MEC. Ministério da Educação. Diretrizes curriculares nacionais do curso de graduação em enfermagem. 2001 Disponível em < http://portal.mec.gov.br/cne/arquivos/pdf/Enf.pdf>. Acesso em 30 de mai. 2021.

OLIVEIRA, W. G., GRIBOSKI, C. M. O estágio supervisionado na formação do enfermeiro revisão integrativa. Trabalho de conclusão de curso. 2018. Disponível em:

<https://www.bdm.unb.br/bitstream/10483/24553/1/2018_WalquiriaGomesDeOliveira tcc.pdf>. Acesso em 30 de mai. 2021. 
EDUCAÇÃO, SAÚDE

ETECNOLOGIA

26 A 28 DE OUTUBRO DE 2021

\section{QUFN}

SAMPAIO, G. B. et al. A. Educação Permanente e o Processo Formativo dos Profissionais da Saúde: Entrelace de Saberes. Revista Eletrônica Acervo Saúde, n. 25, p. e630, 29 jun. 2019. 